\title{
LETTER
}

\section{Tracheobronchial malposition of fine bore feeding tube in patients with mechanical ventilation}

\author{
Ru-Bin Luo, Mao Zhang* and Jian-Xin Gan
}

The increasing prevalence of the use of enteral feeding tubes during critical illness leads to the increased potential for malposition of the tube [1], which may result in severe complications. We report tracheobronchial malposition of feeding tubes in six mechanically ventilated patients.

From January 2008 to August 2011, six multiple trauma patients with mechanical ventilation in the emergency ICU were included in this study. They were male, aged 20 to 84 years, with an injury severity score (ISS) of 29 to 41 . Five patients were intubated and one underwent tracheotomy. Insertion of a fine bore feeding tube (CH10 CM145 Bengmark naso-intestimal tube, Nutricia Medical Devices BV, Switzerland) was tried 1 to 3 days after ICU admission. The first patient had intermittent cough accompanied by slight irritability and tachycardia during insertion. Immediate bronchoscopy confirmed malposition of the feeding tube in the trachea. The feeding tube was inserted without obvious difficulty in the following four patients. However, auscultation detected inconclusive bubbling sounds from the epigastrium after insufflation of air. Later, bronchoscopy for treatment of pneumonia in one patient and chest radiography in three patients revealed trachebronchial malposition of the tube before initiation of enteral nutrition. The sixth patient had no cough during insertion but auscultation detected slight bubbling sounds from the epigastrium after insufflation of air. However, chest computed tomography (CT) confirmed tracheobronchial malposition of the feeding tube (Figure 1). The patient died of septic shock due to blood stream infection 12 days later.

Endotracheal intubation and tracheotomy have been thought to be potential risk factors for trachebronchial malposition of the feeding tube [2]. Mechanically ventilated patients have poor response due to sedation. The metal stylet and weighted tip contribute to the

\footnotetext{
*Correspondence: zmhz@hotmail.com
}

Department of Emergency Medicine, Second Affiliated Hospital, Zhejiang University, School of Medicine; Research Institute of Emergency Medicine, Zhejiang University, No. 88 Jiefang road, Hangzhou, 310009 China rigidity of the feeding tube, which may be easy to pass through the space between the tracheal wall and inflated cuff. It has been advised to monitor the pressure of the endotracheal tube's cuff during insertion [3]. Neither auscultation of bubbling sounds from the epigastrium after insufflation of air nor aspiration of 'gastric content' is thought to be reliable. Measuring the level of carbon dioxide in the feeding tube is a simple way to confirm trachebronchial malposition [4]. The UK National Patient Safety Agency has requested $\mathrm{pH}$ testing of gastric aspirate be used as the first line method for testing trachebronchial malposition, with $\mathrm{pH}$ between 1 and 5.5 as the safe range [5]. X-rays are used as a second line test when all the above methods have failed to confirm the position. Caution should be taken when interpreting chest X-rays with regard to four signs that indicate correct positioning of the tube (Figure 1).

\section{Abbreviations}

$\mathrm{CT}$, computed tomography.

\section{Competing interests}

The authors declare that they have no competing interests.

\section{Published: 18 November 2011}

\section{References}

1. Rassias AJ, Ball PA, Corwin HL: A prospective study of tracheopulmonary complications associated with the placement of narrow-bore enteral feeding tubes. Crit Care 1998, 2:25-28.

2. Roubenoff R, Ravich WJ: Pneumothorax due to nasogastric feeding tubes. Report of four cases, review of the literature, and recommendations for prevention. Arch Intern Med 1989, 149:184-188.

3. Fuchs J, Schummer C, Giesser J, Bayer O, Schummer W: Detection of tracheal malpositioning of nasogastric tubes using endotracheal cuff pressure measurement. Acta Anaesthesiol Scand 2007, 51:1245-1249.

4. Burns SM, Carpenter R, Truwit JD: Report on the development of a procedure to prevent placement of feeding tubes into the lungs using end-tidal CO2 measurements. Crit Care Med 2001, 29:936-939.

5. Lamont T, Beaumont C, Fayaz A, Healey F, Huehns T, Law R, Lecko C, Panesar S, Surkitt-Parr M, Stroud M, Warner B: Checking placement of nasogastric feeding tubes in adults (interpretation of $x$ ray images): summary of a safety report from the National Patient Safety Agency. BMJ 2011, 342:d2586.

\section{doi:10.1186/cc10520}

Cite this article as: Luo R-B, et al:: Tracheobronchial malposition of fine bore feeding tube in patients with mechanical ventilation. Critical Care 2011, 15:454. 


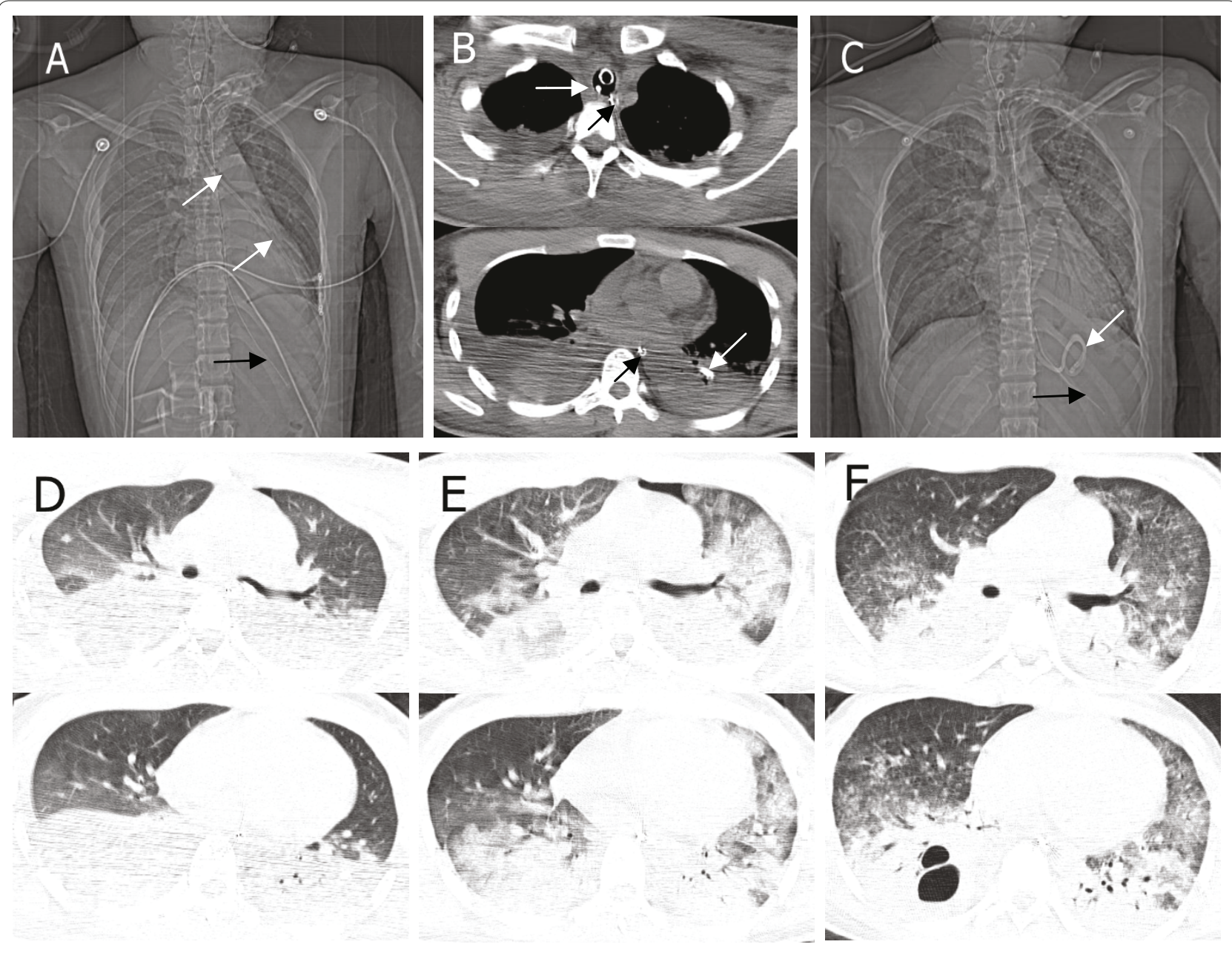

Figure 1. Chest radiological images in the sixth patient with tracheobronchial malposition of the feeding tube. (a,b) Chest computed tomography (CT) on the first day showed the enteral feeding tube (white arrows) was misplaced into the left tracheobronchial tree and a nasogastric tube (black arrow) for drainage of gastric content was in the esophagus and the stomach. (c) Chest radiography on the second day showed the tip of the enteral feeding tube (white arrow) was in the stomach. Four signs indicate the right position: 1) the tube path follows the esophagus; 2) the tube bisects the carina; 3 ) the tube crosses the diaphragm in the middle; 4) the tip is below the left hemi-diaphragm. (d) Chest CT on the first day showed pulmonary contusion, pleural effusion and atelectasis. (e) Progression of bilateral bronchopneumonia was apparent on day 3. (f) Improvement of bronchopneumonia was apparent on day 7. 